\title{
Opinion and Debate
}

\section{Public health prose}

\author{
Dr Fiona Wright \\ Wellbeing editor, London Journal of Primary Care
}

July - the warmest month of the year in the Northern Hemisphere. The SunSmart 2014 Campaign by Cancer UK and NIVEA gives three top tips to protect from sunburn: 1) Spend time in the shade between $11 \mathrm{am}$ and $3 \mathrm{pm}, 2$ ) Cover up with a T-shirt, wide-brimmed hat and sunglasses, and 3) Use at least SPF15 sunscreen, apply regularly and generously. ${ }^{1}$ (You can get free 'enjoy the sun safely' or other posters and leaflets from publications.cancerresearchuk.org/ cancertype/preventionsun.)

In the first instalment of this series I gave an overview of the three core functions of public health practice: health improvement, healthcare public health and health protection. ${ }^{2}$ As promised in these articles, I am taking you through each of them in turn. In this, the fourth article, I further explain the core function of healthcare public health. Healthcare public health is about improving the quality of healthcare an issue at the heart of general practice-led commissioning and community-orientated integrated care.

Following successive changes, we are now over a year past the biggest reorganisation of the NHS since it was created in 1948. The dangers of constant change are clear. For example, it may lead to loss of skilled workforce and weaken the links with partners and communities. In addition the current system is based upon the political ideology of 'the market'. The ability of this market to contain costs and improve quality, particularly equity, is contested. ${ }^{3,4}$ Add to this the threat to public service funding by the harsh financial climate and we see why the current environment presents challenges to improving the quality of health and social care.

However, there are also opportunities. General practitioners (GPs), particularly as commissioners, are now in a position to bring their clinical experience to decision-making fora and advocate for quality. Now, in law, local councils have to ensure the provision of a public health support and expertise to Clinical Commissioning Groups (CCGs). ${ }^{5,6}$ In some areas the extent and nature of this advice is outlined in a 'core offer': a written agreement between your CCG and local council. The preparation of Joint Strategic Needs Assessments (JSNAs) that describe the local population needs are a statutory obligation for Health and Wellbeing Boards. ${ }^{7}$ Using JSNAs can ensure local planning addresses local needs.

In this context there are two key ways that public health can work with primary care and partners to improve the quality of health and social care: 1) By advocating and promoting key principles and approaches; and 2) By using technical public health skills to support their implementation in practice. The principles and the technical public health skills required to improve healthcare quality have remained true through many reorganisations in the past 30 years.

A common understanding of the principles and approaches to improving healthcare quality is developing. The first and foremost is safety. Examples of safety include infection control procedures and appropriate education and training. Other key principles are to ensure that service commissioning and planning is based upon the best evidence of 'what works' and is informed by a full assessment of the needs of the population. ${ }^{7,8}$ We should aim to achieve 'value for quality' and not merely 'value for money'. The integration of health and social care supported by strong community engagement is essential to establish seamless high quality services. This is a key national policy agenda and a topic of discussion throughout this volume of the London Journal of Primary Care. The case for prevention was made in the second of these articles. ${ }^{9}$ Prevention impacts on service quality. For example the management of obesity improves quality of life and reduces healthcare costs for patients with long-term conditions. Care pathways should therefore run from prevention through to rehabilitation or end of life care in order to achieve good outcomes. Finally, 'There is no quality without equality'. ${ }^{10}$ Unless we reach all segments of society then we are not providing quality for the population we serve.

Public health is defined as the science and the art of promoting and protecting health and well-being, preventing ill-health and prolonging life through the organised efforts of society. ${ }^{11}$ Public health practitioners are trained in technical public health skills that support the implementation of approaches to improve healthcare quality. JSNAs produced by public health are usually available on the website of your local 
council. ${ }^{12,13}$ These may be supplemented by specific needs assessments, e.g. for cardiovascular disease. Public health can also often advise you on information sources, such as the Public Health Outcomes Framework, and their interpretation. Other key areas of expertise offered are in the evaluation of health and social care services and in the development of performance measures for monitoring service quality. Lastly health (inequality) impact assessments and health equity audits can be undertaken to assess equality in service provision.

In conclusion we continue to be in a time of change in which we must try to avoid the dangers and maximise the opportunities. There is a solid history of public health principles and skills in healthcare public health. The articles in this journal describe models for developing community-orientated integrated care. Taken together these offer new openings to improve quality and reduce inequalities of health and social care services. 'Summertime is always the best of what might be' according to Charles Bowden. ${ }^{14}$ Saturday 5 July was the 66th birthday of the NHS. ${ }^{15}$ Happy Birthday, dear NHS; Happy Birthday to you!

This prose is written in a personal capacity by Dr Fiona Wright. It does not express the views of any organisation to which I belong or by which I am employed. We would love to hear from you with comments, queries and thoughts. Address for correspondence:phprose@gmail.com

\section{REFERENCES}

1 SunSmart. The Sun Has Got His Hat On. Cancer Research UK, 2014. sunsmart.org.uk/UV-the-sun-andskin-cancer/the-sun-has-got-his-hat-on (accessed 03/ 06/2014).

2 Wright F. Public health prose. London Journal of Primary Care 2014;6:19-20.

3 King's Fund. Market forces alone will not deliver essential changes to hospital services. King's Fund, 2011. www.kingsfund.org.uk/press/press-releases/marketforces-alone-will-not-deliver-essential-changes-hospitalservices (accessed 03/06/2014).

4 Burnham A. Market-based healthcare is the wrong prescription for the NHS. Guardian, 17 February 2012. www.theguardian.com/commentisfree/2012/feb/17/ market-healthcare-nhs-bill (accessed 05/06/2014).

5 Library of the House of Commons. Local authorities public health responsibilities (England). Standard note: SN06844. House of Commons, 2014. www.parliament. uk/briefing-papers/SN06844.pdf (accessed 05/06/2014).

6 Department of Health. Public health in local government: the new public health role of local authorities. Gateway reference: 17876. Department of Health, 2012. www. gov.uk/government/uploads/system/uploads/attachment_ data/file/213009/Public-health-role-of-local-authoritiesfactsheet.pdf (accessed 05/06/2014).

$7 \overline{\text { Department }}$ of Health. Statutory guidance published on Joint Strategic Needs Assessments and Joint Health and Wellbeing Strategies. Department of Health, 2013. webarchive.nationalarchives.gov.uk/20130805112926/ http://healthandcare.dh.gov.uk/jsnas-jhwss-guidancepublished (accessed 03/06/2014).

8 NHS Library and Knowledge Services. Knowledge for commissioning. Prospectus for clinical commissioning groups. NHS: 2013. www.libraryservices.nhs.uk/document uploads/Marketing/2013_CB_Brochure.pdf (accessed 03/06/2014).

9 Wright F. Public health prose, number 2. London Journal of Primary Care 2014;6:39-40

10 South London and Maudsley NHS Foundation Trust. No quality without equality: an action plan for change. SLaM, 2010. brc.slam.nhs.uk/media/24665/no_quality_ without_equality.pdf (accessed 05/06/2014).

11 Faculty of Public Health. What is public health? Faculty of Public Health, 2010. www.fph.org.uk/what_is_ public_health (accessed 05/06/2014).

12 Haringey Council. Joint Strategic Needs Assessment. Haringey Council, 2014. www.haringey.gov.uk/index/ social_care_and_health/health/jsna.htm (accessed 05/ 06/2014).

13 Southwark Council. Southwark Health and Wellbeing Board Joint Strategic Needs Assessment. Southwark Council. www.southwarkjsna.com (accessed 05/06/ 2014).

14 Bowden C. Quotes: Charles Bowden. Goodreads website, n.d. www.goodreads.com/quotes/271974-summertimeis-always-the-best-of-what-might-be (accessed 05/06/ 2014).

15 NHS Choices. The NHS at 65. NHS, 2013. www.nhs.uk/ Livewell/nhs-anniversary/Pages/nhs-65th-anniversary. aspx (accessed 05/06/2014). 